\title{
Estado, mercado, comunidade e avaliação: Esboço para uma rearticulação crítica
}

\author{
Almerindo Janela Afonso
}

RESUMO: A centralidade da avaliação no contexto das políticas educativas contemporâneas tem sido objeto de muitos trabalhos sociológicos, embora as marcas da sua recepção entre nós continuem a ser bastante tênues. Nesse sentido, procura-se neste trabalho compreender as mudanças econômicas e políticas em contextos nos quais ocorreu mais cedo o renascimento conservador e neoliberal, para, em seguida, retirar algumas das implicações desses acontecimentos em termos de reformulação das políticas educativas e avaliativas. Como conseqüência, dado que a redefinição do papel do Estado e a revalorização da ideologia do mercado são dois dos vetores essenciais dessas mudanças, é por referência a esses elementos que se procura elucidar o papel da avaliação educacional, contrapondo, ao mesmo tempo, uma outra rearticulação para pensar a avaliação em relação com a comunidade, numa perspectiva menos reguladora e mais emancipatória. Finalmente, tendo esse quadro teórico em mente, enunciam-se sucintamente algumas das especificidades das mudanças na avaliação educacional que ocorreram em Portugal no início dos anos 90.

* Sociólogo, doutor em Educação (Sociologia da Educação). Professor de Sociologia da Educação e Política Educativa em cursos de graduação e pós-graduação do Instituto de Educação e Psicologia na Universidade do Minho, Portugal. Diretor-adjunto da Revista Portuguesa de Educação; secretário executivo do Centro de Estudos em Educação e Psicologia (CEEP/UM). Email: ajafonso@iep.uminho.pt 
A centralidade da avaliação educacional no contexto das políticas educativas contemporâneas tem sido objeto de alguns trabalhos sociológicos importantes. As perspectivas teóricas e metodológicas adotadas são naturalmente diversas, salientando-se sobretudo um esforço inovador na elaboração de quadros de inteligibilidade quando se convocam contributos das diferentes ciências sociais e humanas para elucidar uma problemática que continua a estar, em grande parte, confinada às teorias pedagógicas e psicológicas. Assim, por exemplo, a tipologia das crises do capitalismo proposta por J. Habermas (1973), bem como a tipologia das estratégias de legitimação compensatória de Hans Weiler (1983), têm sido utilizadas por alguns autores do campo da educação em trabalhos que procuram, de forma exploratória, estabelecer articulações sociológicas entre políticas educativas e avaliativas (cf. Hargreaves 1989, Angulo 1993). O nosso próprio contributo (cf. Afonso 1997a) pretende precisamente dar continuidade a essa linha de análise, embora optando pela construção de um quadro teórico-conceitual relativamente distinto. Em vez de utilizarmos tipologias já constituídas, como algumas das que foram acima referidas - aí enxertando as formas e funções da avaliação que emergiram nas reformas educativas contemporâneas, e que podem ser contextualizadas em face das mudanças sociais mais amplas -, partimos antes para uma compreensão das mudanças econômicas e políticas em países centrais, onde ocorreu mais cedo o renascimento conservador e neoliberal, procurando assim perceber as implicações de tais acontecimentos em termos de reformulação das políticas educativas e avaliativas. Como conseqüência, e dado que a redefinição do papel do Estado e a revalorização da ideologia do mercado são dois dos vetores essenciais dessas mudanças, é por referência a esses elementos que se procura elucidar sociologicamente o papel da avaliação educacional. Finalmente, tendo o mesmo quadro teórico em mente, enunciam-se sucintamente algumas das especificidades das mudanças na avaliação educacional que ocorreram em Portugal nesse mesmo espaço temporal.

\section{Omito do livre-mercado e a manutenção do estado forte}

Nos países capitalistas centrais, os anos 80/90 caracterizaram-se pela emergência das políticas da chamada nova direita. Em The free economy and the strong State - uma obra por muitos considerada essencial para a compreensão dessas políticas nos Estados Unidos e na In- 
glaterra -, Andrew Gamble mostra bem como elas, de forma muito distinta de políticas anteriores, também de direita, foram marcadas por uma singularidade própria: uma combinação da defesa da livre economia, de tradição liberal, com a defesa da autoridade do Estado, de tradição conservadora. $\mathrm{Na}$ base dessa bipolaridade, decisões não-intervencionistas e descentralizadoras passaram a coexistir com outras altamente centralizadoras e intervencionistas, revelando a ambigüidade inerente a essa articulação política que fez com que a nova direita pudesse "parecer sucessivamente libertária e autoritária, populista e elitista" (Gamble 1994, p. 36). Como sintetiza um autor,

para os neoliberais a ênfase é sempre na liberdade de escolha, no indivíduo, no mercado, no governo mínimo e no laissez-faire; enquanto os neoconservadores dão prioridade a idéias como o autoritarismo social, a sociedade disciplinada, a hierarquia e a subordinação, a nação e o governo forte. (Chitty 1994, p. 23)

O resultado dessas tensões e contradições - decorrentes de uma fórmula política que exige um Estado limitado (portanto, mais reduzido e circunscrito nas suas funções) mas, ao mesmo tempo, forte (no seu poder de intervenção) - produziu, em certo sentido, um desequilíbrio importante a favor do Estado e em prejuízo do livre-mercado. Designado já como o "paradoxo do Estado neoliberal", esse fato significa basicamente que, "embora o neoliberalismo possa ser considerado como uma doutrina que prega o Estado autolimitador, o Estado tem-se tornado mais "poderoso' sob as políticas neoliberais de mercado" (Peters 1994, p. 213).

De fato, se tomarmos como referência a concepção neoliberal proposta por autores como Robert Nozick na sua obra Anarchy, State and utopia, veremos que a nova direita adotou uma versão liberal bastante mitigada. ${ }^{1} \mathrm{Na}$ visão liberal radical, a economia é o resultado de uma harmonia de interesses gerada por trocas voluntárias entre indivíduos livres e autônomos, e o Estado é apenas o garante dessa ordem espontaneamente gerada pelo mercado. Nessa linha de pensamento, admite-se como possível e desejável a existência de um mercado totalmente livre da tutela estatal, aceitando apenas como tarefas legítimas de um "Estado mínimo" aquelas que se restrinjam "às funções de proteção contra a violência, o roubo e a fraude, bem como às funções que permitam o cumprimento de contratos" (Nozick 1988, p. 7). ${ }^{2}$ 
No entanto, não parece ter sido isso que aconteceu em países centrais. Ao contrário, o mercado não ressurgiu como um processo espontâneo, completamente fora do âmbito do Estado, mas como um sistema promovido e controlado, em grande parte, pelo Estado. ${ }^{3} \mathrm{E}$ não nos parece que tenha sido assim apenas pelo fato de, como refere Bill Schwarz (1992, p. 111), no capitalismo avançado, o Estado autoritário se tornar necessário ao projeto neoliberal para vigiar ativamente a imposição dessa nova ordem representada pelo mercado. O que ocorre, mais precisamente, é que, como observa Hanf, nem os mercados são fenômenos naturais nem, tampouco, pode-se pensar essa questão como se estivesse em causa uma simples escolha entre um mercado livre ou uma economia regulada pelos governos. De fato, como conclui este último autor, "todas as economias de mercado são sistemas mistos de regulamentação governamental e de forças de mercado" (Hanf 1994, p. 27).

Há, no entanto, especificidades na forma como as políticas da nova direita desenharam as relações entre Estado e mercado. Se, por um lado, o mercado tout court teve uma notória expansão na forma de algumas políticas de privatização e de liberalização da economia, também é verdade que, apesar da crise fiscal e dos ataques neoliberais, o Estadoprovidência resistiu - e isso, por outro lado, constituiu igualmente um importante obstáculo à maior expansão do mercado.

Mas a resistência do Estado-providência não significou a manutenção do statu quo. De fato, as coligações de direita que estiveram no poder em países como a Inglaterra puseram em prática outras estratégias para tentar gerir a tensão resultante da não diminuição das exigências em relação aos direitos sociais (nomeadamente na área da saúde e da educação) e da crescente escassez de receitas provenientes dos impostos (entretanto muito perto dos limites eleitoralmente suportáveis). Como refere Brian Salter (1995), numa situação como a descrita, há que procurar uma das seguintes estratégias: ou se tenta redefinir o que se entende por direitos ligados ao Estado-providência (uma questão essencialmente ideológica), ou se consegue um melhor equilíbrio entre a oferta e a procura (com uma maior eficiência na utilização das receitas provenientes dos impostos) ou, ainda, se encontram fontes alternativas de financiamento. A primeira estratégia exige convencer os cidadãos a reduzir ou, pelo menos, a não aumentar os seus direitos - o que não é uma estratégia plausível a curto prazo dada a "hegemonia dos valores do Estado-providência". A segunda estratégia implica redirecionar a procura para o setor privado - 0 que pressupõe que se criem incentivos para que esse setor possa aumen- 
tar sua capacidade de atendimento, e os cidadãos sejam persuadidos de que não perdem direitos porque poderão fazer escolhas mais amplas e ter acesso a serviços de melhor qualidade. Finalmente, a terceira estratégia, muito mais sutil, supõe a adoção de medidas tendentes a atenuar as fronteiras entre o setor público e o setor privado, de modo a permitir que se torne igualmente menos nítida a distinção entre os direitos sociais e os direitos individuais. Isso, por sua vez, refere ainda Brian Salter, pode levar ao enfraquecimento da hegemonia dos valores do Estado-providência e, conseqüentemente, a uma redução da procura dos serviços públicos. Exemplos dessas políticas são, entre outros, os mercados internos (internal markets) e os incentivos para uma economia mista de bem-estar social (cf. Salter 1995). Foram precisamente algumas dessas estratégias, implementadas pela nova direita, que configuraram o que alguns autores têm vindo a designar como mecanismos de quase-mercado.

$\mathrm{Na}$ realidade, mais do que à confinação do Estado e à expansão do mercado, assistiu-se, em muitos casos, à interpenetração desses elementos, com arranjos específicos consoante as conjunturas nacionais, os quais resultaram numa configuração particular se comparada com as de outros períodos históricos da evolução do capitalismo. É isso precisamente que, do nosso ponto de vista, constitui um dos aspectos distintivos mais importantes das políticas de convergência neoliberal e neoconservadora; e é isso também que seguramente constitui um dos principais vetores da redefinição do papel do Estado neste período. ${ }^{4}$ Como escreve Reg Whitaker (1992), muitas dessas tendências põem em causa a natureza do próprio Estado capitalista, obrigando não apenas a redefinir as fronteiras tradicionais entre os setores público e privado, mas também a repensar a questão da relativa autonomia do Estado. Daí, igualmente, a centralidade do conceito de quase-mercado.

$\mathrm{Na}$ definição de Le Grand - um dos autores que têm vindo a discutir a criação de quase-mercados no âmbito do Estado-providência -, quase-mercados são mercados porque substituem o monopólio dos fornecedores do Estado por uma diversidade de fornecedores independentes e competitivos; são quase porque diferem dos mercados convencionais em aspectos importantes. Assim, por exemplo, as organizações competem por clientes mas não visam necessariamente à maximização de seus lucros; o poder de compra dos consumidores não é necessariamente expresso em termos monetários e, em alguns casos, os consumidores delegam a certos agentes a sua representação no mercado (cf. Le Grand 1991, pp. 1.259-1.260). 
Esses mecanismos de quase-mercado - porque igualmente introduzidos nos sistemas educativos - justificam algumas referências e considerações que faremos a seguir.

\section{Quase-mercados em educação}

Como refere Roger Dale (1994, p. 112), em educação o termo mercado é mais conotativo do que denotativo. Isso significa que, por vezes, quando se fala de "mercadorização da educação" não se trata senão da implementação de mecanismos de "liberalização" no interior do sistema educativo, ou da introdução de elementos de "quase-mercado". De fato, analisando alguns casos concretos de políticas educacionais da nova direita, esse autor conclui que "o que está em questão são novas formas e combinações de financiamento, fornecimento e regulação da educação", diferentes das formas tradicionais exclusivamente assumidas pelo Estado. Todavia, tal como aconteceu noutros setores, a criação de quase-mercados em educação pode mesmo "incluir um papel maior, e/ou modificado para o Estado (e não necessária ou automaticamente um papel menor)" (Dale 1994, pp. 110-111). ${ }^{5}$

Aliás, o Estado não pode deixar de ter um papel ativo sendo "o mercado uma criação política, concebida para fins políticos", como acentua Stewart Ranson. Por essa razão, parece-nos importante a observação desse autor quando acrescenta que "o mercado em educação não é o mercado clássico da concorrência perfeita, mas um mercado cuidadosamente regulado e com controles rígidos" (Ranson 1993, p. 338). ${ }^{6}$ Nesse mesmo sentido, escreve também R. Hatcher, a regulação que é feita pelo Estado não é contraposta ao mercado, pois a criação e a manutenção do mercado depende do Estado. Aliás, a introdução de quase-mercados no setor público, em geral, e na educação, em particular, evidencia bem essas relações. De fato, acrescenta R. Hatcher (1994, p. 45), "a educação distingue-se não só do setor privado como também de outras áreas do setor público pelo fato de os poderes do Estado, que mantêm o mercado, se entrelaçarem com outros poderes que controlam o próprio conteúdo da educação". É, aliás, essa combinação específica de regulação do Estado e de elementos de mercado no domínio público que, na nossa perspectiva, explica que os governos da nova direita tenham aumentado con- 
sideravelmente o controle sobre as escolas (nomeadamente pela introdução de currículos e exames nacionais) e, simultaneamente, tenham promovido a criação de mecanismos como a publicitação dos resultados escolares, abrindo espaço para a realização de pressões competitivas no sistema educativo.

Na perspectiva de M. Apple, por exemplo, essa aparente contradição pode não ser tão substancial como se esperaria dado que, numa época de crise e de perda de legitimidade, a introdução de um currículo nacional e de uma avaliação também em nível nacional transmite a idéia de que o governo está preocupado com os consumidores e com a necessidade de elevar os níveis educacionais - o que é, afinal, a principal preocupação do mercado. Para esse autor, a criação de um currículo nacional, o estabelecimento de normas-padrão nacionais (national standards) e a realização de testes também em nível nacional são mesmo condições prévias para que se possam implementar políticas de privatização e mercadorização da educação, representando, portanto, um compromisso ideal no âmbito da coligação de direita (cf. Apple 1993, p. 230). Curiosamente, os setores neoliberais ingleses não estavam inicialmente dispostos a apoiar a imposição de um controle central sobre o currículo. Como lembra Clyde Chitty, foi mesmo necessário convencê-los de que

(...) um currículo nacional não era necessariamente incompatível com a promoção dos princípios do livre-mercado. Isso poderia, afinal, ser uma boa justificação para realizar testes de avaliação nacionais em determinadas etapas da carreira escolar dos alunos, proporcionando, desse modo, importantes dados e informações aos pais sobre as características desejáveis ou indesejáveis de cada escola. Em outras palavras, informações suplementares aos consumidores proporcionadas pelos resultados dos testes poderiam realmente ajudar um sistema de mercado a operar de modo mais eficaz. (Chitty 1994, p. 24)

Por isso, hoje em dia parece ser relativamente consensual naqueles setores que a imposição de um currículo nacional e a introdução de exames nacionais não são, de fato, incompatíveis com a promoção de valores de mercado, embora a adoção dessas alterações tenha introduzido no sistema educativo inglês importantes tensões a que os professores deram voz. ${ }^{7}$ 


\section{OEstado-avaliador e a ênfase nos resultados / produtos educacionais}

Se no nível dos sistemas educativos, em países como os Estados Unidos e a Inglaterra, a avaliação foi essencial para a promoção de quase-mercados, também mostrou ser uma estratégia útil, no âmbito mais geral, para apoiar as tentativas de transformação dos valores próprios do domínio público. Sendo este o espaço onde se expressam os propósitos coletivos de uma dada sociedade - remetendo, nomeadamente, para os direitos e as necessidades sociais que são estabelecidos por meio de escolhas publicamente construídas -, o domínio público deve preservar e atender valores específicos como a igualdade, a justiça e a cidadania.

No entanto, foram estes e outros valores semelhantes que estiveram (e continuam a estar) ameaçados perante a introdução de elementos de mercado e outras lógicas específicas do setor privado que, entre outros modos, têm sido viabilizados pela utilização política e administrativa de certas modalidades de avaliação. Como mostra Mary Henkel em Government, evaluation and change - estudo que cobre um período decisivo de transformações nas políticas públicas inglesas, entre 1983 e 1989 -, "o governo identificou a avaliação como uma componente significativa na sua estratégia de conseguir alguns objetivos decisivos: controlar as despesas públicas, mudar a cultura do setor público e alterar as fronteiras e a definição das esferas de atividade pública e privada" (cf. Henkel 1991a, p. 9). Desse modo, a avaliação reaparece claramente relacionada com funções gestionárias tendendo a ser, como refere $\mathrm{E}$. House (1993, p. x), uma "avaliação centrada na eficiência e na produtividade sob o controle direto do Estado". Considerando esses vetores, torna-se agora mais evidente a razão pela qual, no período em análise, uma das mudanças importantes, tanto fora como dentro do contexto educacional, foi precisamente a ênfase genérica na avaliação dos resultados (e produtos), e a conseqüente desvalorização da avaliação dos processos, independentemente da natureza e dos fins específicos das organizações ou instituições públicas consideradas. ${ }^{8}$

Como referem David Osborne e Ted Gaebler (1992, p. 139), ${ }^{9}$ o simples fato de as agências públicas terem que definir os resultados ou indicadores-alvo (benchmarks) que pretendem alcançar obriga-as a pensar nos seus próprios fins, os quais, freqüentemente, ou não são claros ou não estão bem definidos. Assim, acrescentam esses mesmos autores, os "governos empreendedores" devem procurar mudar o sistema de re- 
compensas, pondo a tônica nos resultados, porque "quando as instituições são financiadas de acordo com os resultados, elas tornam-se obsessivas em relação a seu desempenho", e é isso que é necessário incentivar. No relatório intitulado Reinventar a administração pública, elaborado sob a direção do vice-presidente americano Al Gore, e fortemente influenciado pela obra de David Osborne e Ted Gaebler, afirma-se a certa altura: "O nosso caminho é claro: temos de transitar de sistemas que responsabilizam as pessoas por processos, para sistemas que as tornam responsáveis por resultados" (Al Gore 1994, p. 55). De acordo com esses pressupostos, sem resultados mensuráveis (que devem ser tornados públicos) não se consegue estabelecer uma base de responsabilização (accountability) credível, tornando-se igualmente mais difícil a promoção da competição entre setores e serviços - em ambos os casos, duas dimensões essenciais das novas orientações políticas e administrativas.

Em termos de política educativa, mais especificamente, trata-se agora de tentar conciliar o Estado-avaliador - preocupado com a imposição de um currículo nacional comum e com o controle dos resultados (sobretudo acadêmicos) ${ }^{10}$ - e a filosofia de mercado educacional assente, nomeadamente, na diversificação da oferta e na competição entre escolas. Sendo a avaliação um dos vetores fundamentais nesse processo, é necessário saber qual a modalidade que melhor serve à obtenção simultânea daqueles objetivos. É isso que procuraremos fundamentar a seguir.

\section{A avaliação estandardizada criterial com publicitação de resultados}

Podendo admitir-se (e por razões essencialmente dedutivas) que a modalidade de avaliação mais congruente com a ideologia do mercado é a avaliação normativa, constata-se, no entanto, à medida que se avança na compreensão das especificidades das atuais políticas educativas, que não há evidência empírica para sustentar essa hipótese. Não que (teoricamente) a avaliação normativa não seja a mais adequada para promover os valores neoliberais baseados na comparação dos indivíduos, na competição e em outras regras de mercado. Por alguma razão, obras marcantes do neoliberalismo educacional, como Politics, markets, and America's schools de J. Chubb e T. Moe (1990), propugnaram por esses princípios e valorizaram a utilização de modalidades de avaliação estandardizada normativa. 
De fato, se as teorias vindas dos setores neoliberais mais radicais tivessem sido postas em prática, essa seria naturalmente a modalidade de avaliação que faria sentido num contexto de forte retração do Estado (Estado-mínimo) e de grande expansão do mercado. Nesse sentido, no limite, o Estado - não pondo qualquer obstáculo a uma maior diversificação curricular e admitindo a transmissão de conteúdos e objetivos educacionais não sujeitos a qualquer uniformização nacional - induziria a predominância de formas de avaliação congruentes com a mercadorização da educação escolar. ${ }^{11}$ Mas, como já procuramos demonstrar, isso não ocorreu assim e, nesse sentido, as alterações nas políticas avaliativas acabaram também por refletir a filosofia das mudanças mais gerais em curso nesse período. Assim, a avaliação estandardizada criterial, isto é, a avaliação que visa ao controle de objetivos previamente definidos (quer como produtos, quer como resultados educacionais), é que foi sendo gradualmente apontada como um dos traços distintivos das mudanças nas políticas avaliativas, tornando-se um instrumento importante para a implementação da agenda educacional da nova direita. Isso porque, se pela introdução da avaliação estandardizada criterial se pode favorecer a expansão do Estado, pela publicação dos resultados dessa mesma avaliação pode promover-se a expansão do mercado.

Depois deste breve percurso de fundamentação, parecerá agora óbvio que, tendo o Estado reforçado o seu poder de regulação e retomado o controle central (nomeadamente sobre o currículo escolar), a avaliação tenha, de forma congruente, sido acionada como suporte de processos de responsabilização ou de prestação de contas relacionados com os resultados educacionais e acadêmicos, passando estes a ser mais importantes do que os processos pedagógicos (que teriam implicado outras formas de avaliação). Em síntese, se é verdade que emergiu o Estado-avaliador, também é verdade que as mudanças nas políticas avaliativas foram igualmente marcadas pela introdução de mecanismos de mercado. Por isso, nesse contexto politicamente ambivalente, e nesse período específico que analisamos, o controle sobre os resultados escolares não é subordinado, nem se restringe, a uma mera lógica burocrática - o que torna a atuação do Estado nesse campo claramente distinta das estratégias adotadas em outras épocas e em outros contextos históricos, explicandose também por aí as especificidades contemporâneas.

A figura 1 resume grande parte do percurso analítico por nós efetuado. Contém, porém, alguns elementos que não foram ainda objeto de problematização e que, por isso, serão a seguir discutidos. Trata-se, em síntese, de uma construção teórica que contém duas dimensões importantes: uma, 
mais descritiva e analítica, pretende dar conta, com suficiente consistência e fundamentação, das mudanças ocorridas nas políticas avaliativas neoliberais e neoconservadoras que tiveram lugar, ao longo dos anos 80 e início dos anos 90, em contextos sociais e políticos determinados; a outra, assumidamente mais normativa, procura inscrever nas insuficiências da primeira uma contraproposta alternativa assente no que pensamos ser uma utopia realizável: a defesa de uma concepção mais radical das potencialidades educacionais (ainda não esgotadas) da avaliação formativa, ancorada num novo (des)equilíbrio entre o pilar da regulação e o pilar da emancipação.

\section{Figura 1}

\section{A avaliação no contexto das mudanças sociopolíticas contemporâneas}

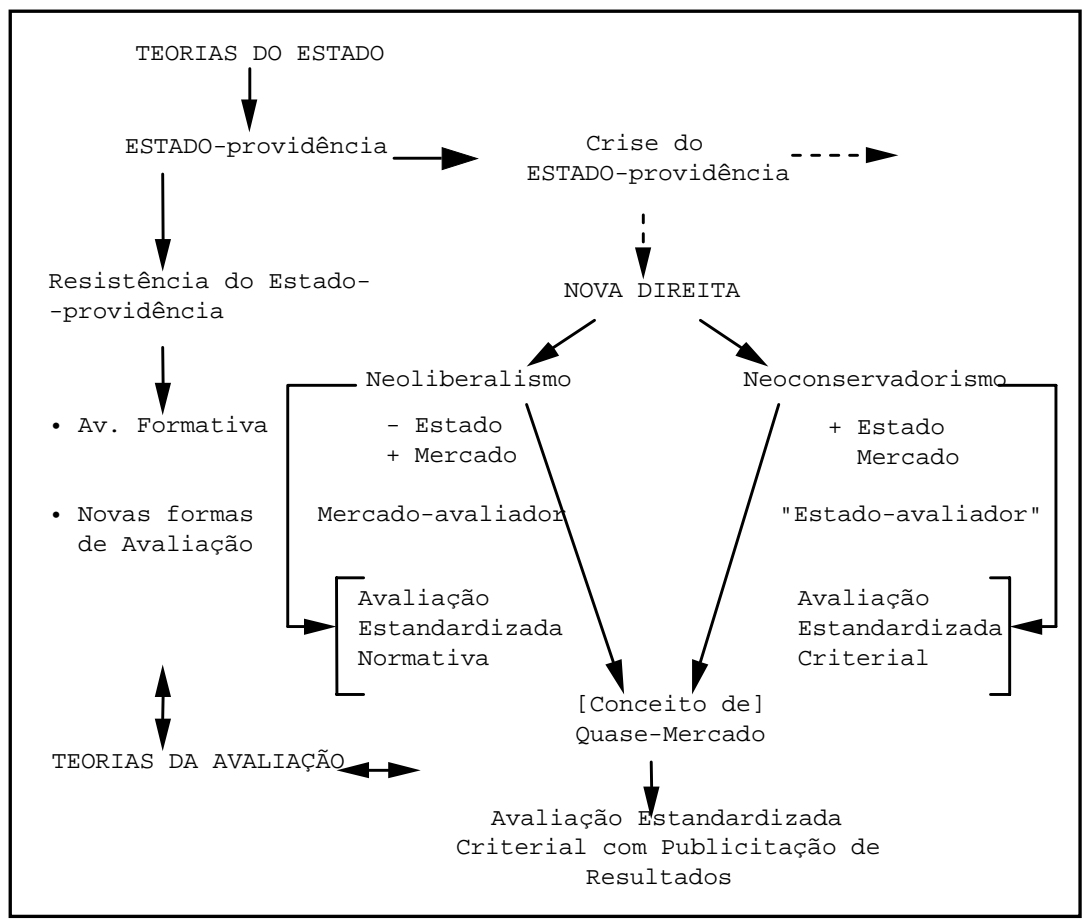

As teorias do Estado sinalizadas na figura 1 devem ser um dos pontos de partida para a compreensão da especificidade do Estado-pro- 
vidência cuja crise se tem procurado solucionar pela implementação de políticas sociais e econômicas híbridas - as quais, como seria de esperar, tiveram importantes reflexos nas reformas educativas mais recentes. ${ }^{12}$

Se, no que à educação escolar pública diz respeito, uma das dimensões mais expressivas dos valores neoconservadores foi a emergência do Estado-avaliador, em termos de valores neoliberais o mais importante terá sido a introdução de mecanismos de mercado nesse mesmo domínio. Mas como essas dimensões se (con)fundiram em articulações muito específicas de país para país haveria que encontrar uma forma de avaliação (ideal-típica) capaz de dar conta (genericamente) dessas particularidades, sendo igualmente suscetível de atender quer aos pressupostos subjacentes ao mercado educacional quer ao Estado-avaliador. Para além de encontrar justificação do ponto de vista da teoria da avaliação e da sociologia da avaliação (cf. Afonso 1997a, sobretudo capítulo I), a modalidade de avaliação criterial - necessariamente validada do ponto de vista técnico e científico (portanto, estandardizada ou aferida), mas sujeita ao controle pelo mercado através da publicitação dos respectivos resultados - é a modalidade de avaliação mais congruente com as mudanças estudadas. Aliás, como já vimos anteriormente, essa conclusão é também reforçada empiricamente pelo fato de ter sido esta a forma de avaliação que (re)emergiu e que foi mais valorizada nas agendas educacionais e nas políticas educativas referenciadas. Designada aqui como avaliação estandardizada criterial com publicitação de resultados, essa modalidade de avaliação permite evidenciar, melhor que qualquer outra, o já designado "paradoxo do Estado neoliberal": por um lado, o Estado quer controlar mais de perto os resultados escolares e educacionais (tornando-se assim mais Estado, Estado-avaliador), mas, por outro, tem que partilhar esse escrutínio com os pais vistos agora como clientes ou consumidores (diluindo também por aí algumas fronteiras tradicionais, e tornando-se mais mercado e menos Estado). ${ }^{13}$ Produz-se assim um mecanismo de quase-mercado em que o Estado, não abrindo mão da imposição de determinados conteúdos e objetivos educacionais (de que a criação de um currículo nacional é apenas um exemplo), permite, ao mesmo tempo, que os resultados/produtos do sistema educativo sejam controlados pelo mercado.

Procurando agora colmatar algumas insuficiências e limites inerentes a um enquadramento teórico-conceitual, até aqui quase exclusivamente centrado na explicação e na contextualização de algumas mudanças nas políticas educativas e avaliativas iniciadas e desenvolvidas em países centrais - mas que, espera-se, não deixará (apesar disso ou também por isso) de ser útil para entender e situar o que ocorreu, ou não, entre nós 
no período em análise -, queremos agora desenvolver outras dimensões, também sinalizadas na figura 1, que apontam para um outro tipo de política educativa e para uma outra agenda avaliativa. Trata-se, essencialmente, de completar o enquadramento teórico-sociológico que temos estado a desenvolver introduzindo uma visão mais prospectiva que contraponha a lógica da emancipação (mais centrada na Comunidade) à lógica da regulação, uma vez que é esta última que tem sido reforçada pelas políticas avaliativas do neoliberalismo conservador caracterizadas, precisamente, por terem acentuado (ainda mais) o desequilíbrio a favor do Estado e do mercado, em prejuízo da comunidade. ${ }^{14}$

\section{A melhoria qualitativa do Estado-providência, a avaliação formativa e o retorno à emancipação}

Retomando considerações que desenvolvemos noutras oportunidades, pensamos, em síntese, que o que aqui designamos por melhoria qualitativa do Estado-providência passa também necessariamente por um novo equilíbrio entre o pilar da regulação e o pilar da emancipação, bem como pela reabilitação da reciprocidade perante a troca e a redistribuição. ${ }^{15}$

\section{Quadro 1 - A avaliação}

formativa numa nova articulação entre o Estado e a comunidade

\begin{tabular}{|c|c|c|c|}
\hline \multicolumn{3}{|c|}{ AVALIAÇÃO ESTANDARDIZADA (AFERIDA) } & $\begin{array}{l}\text { AVALIAÇÃO NÃO } \\
\text { ESTANDARDIZADA }\end{array}$ \\
\hline $\begin{array}{l}\text { AVALIAÇÃO } \\
\text { CRITERIAL }\end{array}$ & $\begin{array}{l}\text { AVALIAÇÃO } \\
\text { CRITERIAL COM } \\
\text { PUBLICITAÇÃO } \\
\text { DE RESULTADOS }\end{array}$ & $\begin{array}{l}\text { AVALIAÇÃO } \\
\text { NORMATIVA }\end{array}$ & $\begin{array}{l}\text { AVALIAÇÃO } \\
\text { FORMATIVA }\end{array}$ \\
\hline ESTADO & $\begin{array}{l}\text { [conceito de] } \\
\text { QUASE- } \\
\text { MERCADO }\end{array}$ & MERCADO & $\begin{array}{l}\text { ESTADO-Providência } \\
\text { COMUNIDADE } \\
\text { ALUNO/ } \\
\text { PROFESSOR }\end{array}$ \\
\hline \multicolumn{3}{|c|}{ REGULAÇÃO } & EMANCIPAÇÃO \\
\hline \multicolumn{3}{|c|}{ 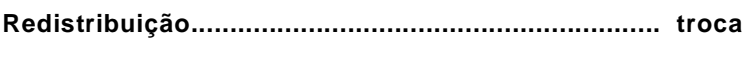 } & $\begin{array}{l}R E G U L A C ̧ A ̃ O \\
\text { reciprocidade }\end{array}$ \\
\hline
\end{tabular}


Como refere Boaventura de Sousa Santos (1991, pp. 27-37), dos três princípios (Estado, mercado e comunidade), o princípio da comunidade é o "mais bem colocado para instaurar uma dialéctica positiva com o pilar da emancipação, e restabelecer assim a vinculação da regulação e da emancipação". Concorre para isso, continua esse autor, o fato de o princípio da comunidade conter "virtualidades epistemológicas" que o tornam um eixo importante neste redimensionamento entre regulação e emancipação porque, entre outras razões, alguns de seus elementos constitutivos (como o prazer, a participação e a solidariedade) têm sido focos de resistência à invasão da racionalidade cognitivo-instrumental da ciência e da técnica. Assim, a comunidade pode tornar-se "o campo privilegiado do conhecimento-emancipação" se este for concebido como trajetória que leva o indivíduo de um estado de ignorância a um estado de saber que se pode designar por solidariedade (um conhecimento que "progride do colonialismo para a solidariedade"); e se a solidariedade for "o processo, sempre inacabado, de capacitação para a reciprocidade através da construção de sujeitos que a exercitem" ou "sujeitos capazes de reciprocidade". Por isso, é necessário romper com o "conhecimento-regulação" que transformou o outro em objeto para, de uma forma radicalmente nova, passar a "constituir o outro numa rede intersubjectiva de reciprocidades". Trata-se, portanto, de um "conhecimento-emancipação que avança do colonialismo para a solidariedade, pela criação de relações sujeito-sujeito estabelecidas no seio de comunidades interpretativas". Em síntese,

o saber novo só será novo se for simultaneamente uma nova inteligibilidade, uma nova ética, uma nova política e uma nova estética. Para isso tem de se exercitar no recurso criativo aos elementos constitutivos do princípio da comunidade, à solidariedade, à participação e ao prazer. (Santos 1991, p. 39)

Na nossa perspectiva, uma teoria como essa - assente na valorização do conhecimento-emancipação, na intersubjetividade e na reinvenção da comunidade, bem como na reciprocidade, participação e solidariedade - é extremamente oportuna para fundamentar a defesa de uma política avaliativa radicalmente diferente daquela que atravessou e caracterizou os anos 80 e 90. É, aliás, com base em seus pressupostos que defendemos ser possível (e desejável) relocalizar a avaliação formativa dentro de um projeto de educação emancipatória, considerando-a um eixo fundamental na articulação entre o Estado e a comunida- 
de. De fato, a avaliação formativa, sem deixar de estar relacionada com - Estado, como lugar de definição de objetivos educacionais e espaço de cidadania, parece ser a forma de avaliação pedagógica mais congruente com o princípio da comunidade e com o pilar da emancipação. ${ }^{16}$ Pensamos mesmo que a avaliação formativa deve ser considerada no âmbito dos direitos sociais e educacionais que caracterizam o Estadoprovidência e que, como lembra também Boaventura Santos, foram direitos essencialmente obtidos por pressão do princípio da comunidade. Por outro lado, só a avaliação formativa, como ação pedagógica estruturada na base de relações de reciprocidade, e intersubjetivamente validada (cf. Afonso 1995b), pode promover um novo desequilíbrio no pilar da regulação a favor do pilar da emancipação. ${ }^{17}$ Nos limites gráficos (e conceituais) de um esquema, é isso precisamente que o quadro 1 sintetiza: um novo ponto de chegada que não é mais, afinal, do que um outro ponto de partida para refletir a problemática da avaliação pedagógica numa perspectiva sociológica crítica. Uma perspectiva que, segundo cremos, não deixa certamente de ser simultaneamente crítica e utópica, na linha de muitos outros autores. Mas esse quadro serve naturalmente também para perceber os nossos próprios avanços e recuos em relação à problemática da avaliação educacional.

\section{A avaliação no ensino básico na agenda da reforma educativa em Portugal}

No que diz respeito às políticas educativas para o ensino não-superior, a repercussão das mudanças neoliberais só começa a se fazer sentir em Portugal no momento em que o novo modelo de avaliação dos alunos do ensino básico (Despacho Normativo nº 98-A/92) já está em fase de implementação nas escolas. Nessa coincidência temporal poderá residir uma das causas que impediram a realização cabal da nova proposta de avaliação dos alunos: os aspectos mais democráticos do novo modelo de avaliação, como a avaliação formativa e a obrigatoriedade de realizar formas de compensação educativa (destinadas a viabilizar, em condições adequadas e justas, o caráter excepcional da retenção dos alunos e a promoção da Escola para todos), acabaram (paradoxalmente) por colidir com condições sociais e políticas que seriam as mais desfavoráveis à sua promoção. De fato, a introdução da avaliação formativa (que é, do nosso ponto de vista, um dos instrumentos fundamentais da escola de- 
mocrática) depara-se com uma nova fase de desenvolvimento da escola meritocrática, iniciada em meados dos anos 80 , num contexto de reivindicação crescente de formas de avaliação mais seletivas e de retorno aos exames nacionais. De fato, a consagração, no início dos anos 90 , da modalidade de avaliação formativa (que atrás procuramos relacionar com o pilar da emancipação) surge num contexto político muito diferente daquele em que tinha emergido pela última vez, no pós-25 de abril de $1974 .{ }^{18}$ Neste último contexto histórico, a avaliação formativa fez parte do processo de democratização da sociedade portuguesa - mas ninguém diria agora o mesmo diante da emergência neoliberal e neoconservadora polarizada, em termos de modalidades de avaliação publicamente defendidas, quer na adesão à avaliação aferida, ${ }^{19}$ quer na reclamação dos exames nacionais. ${ }^{20}$

Entretanto, como lembra Stephen Stoer, se é verdade que, nesse período, a assunção da crise do fordismo, em Portugal, acaba também por traduzir-se numa crise da escola de massas e num novo desenvolvimento da escola meritocrática, também é verdade que o Estado modernizador não deixa de investir "numa continuada consolidação da escola oficial (de massas) para todos" (cf. Stoer 1994, p. 17). Esse processo, tenso e contraditório, que tem sido designado, em diferentes oportunidades, como "a simultânea crise e consolidação da escola de massas em Portugal" (Stoer e Araújo 1992, Stoer 1994) poderá também contribuir para explicar o fato de as propostas saídas da reforma educativa de meados dos anos 80 contemplarem (simultaneamente) modalidades de avaliação pedagógica muito díspares, como sejam a avaliação formativa e a avaliação aferida. Mais concretamente, queremos sugerir que a presença da avaliação formativa pode ser entendida como um indicador da vontade do Estado continuar a realizar a "consolidação da escola de massas" enquanto a introdução da avaliação aferida, ao contrário, pode ser justificada como uma decorrência da constatação de que existe uma "simultânea crise" dessa mesma escola, cuja resolução ou mesmo atenuação exige (pelo menos simbolicamente) a consagração de outras formas de avaliação. Assim, a diferenciação das modalidades de avaliação previstas para a escola básica de massas acabou por revelar a tensão entre a escola democrática e a escola meritocrática - tensão essa igualmente alimentada pelo gradual predomínio das necessidades do processo de acumulação (a exigir um sistema educativo mais elitista, um currículo mais instrumental e uma avaliação mais seletiva). ${ }^{21}$

É também importante salientar que a não concretização dos aspectos mais democráticos contidos na regulamentação da avaliação dos 
alunos do ensino básico não foi independente dos recursos, dos atores e das condições materiais existentes nas escolas. A desvalorização da avaliação formativa, num contexto de crescente predomínio de uma cultura social de discriminação (cf. Afonso 1995b), bem como a insuficiência de recursos e condições de sucesso para a realização de uma escola básica democrática com qualidade científica e pedagógica, não deixa dúvidas sobre a fragilidade do nosso semi-Estado-providência na educação, e sobre a escassa interiorização dos direitos humanos básicos na escola pública. ${ }^{22}$

Todavia, o debate em torno das políticas educativas nestes últimos anos em Portugal revela que, apesar do espírito do tempo, não há unanimismo em termos de visões do mundo, continuando a ser possível inscrever na agenda política perspectivas educacionais progressistas e emancipatórias. É nesse sentido que pode ser pensada (como utopia realizável) uma avaliação formativa que articule os interesses do Estado e da comunidade, vise a altos padrões de qualidade científica e democrática na escola básica, valorize a autonomia profissional dos professores, e recupere para o processo pedagógico novas formas de participação, de solidariedade e de reciprocidade.

\section{Notas}

1. Trabalhos mais recentes observam mesmo que, comparativamente com a obra de Hayek, Anarquia, Estado e utopia de Robert Nozick não teve o impacto político que se poderia pensar. Ver a esse propósito, por exemplo, Brian Lund (1996).

2. Entretanto, em obra mais recente, Robert Nozick (1992, p. 15) deixa claro ter reconsiderado muitos dos postulados originais de Anarquia, Estado e utopia - "Habiendo escrito un libro de filosofía política que delineaba una perspectiva particular que hoy no me satisface (...), soy muy consciente de la dificultad de rehuir un pasado intelectual". E mais à frente escreve: "La posición libertaria que propuse una vez hoy me parece seriamente inadecuada, en parte porque no entretejía cabalmente las consideraciones humanitarias y las actividades cooperativas para las que dejaba espacio"(id., ibid., p. 227).

3. Veja-se também a argumentação em torno do que se designa por "Estado híbrido" desenvolvida por Phillip Cooper (1995).

4. À primeira vista, essa perspectiva parece muito diferente da que é defendida, por exemplo, por Boaventura Santos quando caracteriza a fase mais recente do capitalismo nos países centrais como "uma fase de re-hegemonização 
do princípio do mercado e de colonização, por parte deste, do princípio do Estado e do princípio da comunidade, de que a reaganomics e o thatcherismo são chocantes manifestações" (Santos 1994, pp. 204-205). No entanto, e na nossa perspectiva, quando atendemos a outras passagens da mesma obra, verificamos que a referência à "colonização do princípio do Estado por parte do princípio do mercado" aproxima-se muito do conceito de quase-mercado - ou, pelo menos, as conclusões são muito semelhantes (cf. Santos 1994, pp. 215-216 e 219-220, por exemplo).

5. Numa análise comparativa relativa às políticas de escolha educacional da nova direita, Jim Carl afirma também: "Contrary to the claim that parental choice 'rolls back the State' and therefore debureaucratizes and depoliticizes education, 'choice' did not reduce central State control of schooling in England and the United States but, rather, reconstituted it at different levels" (Carl 1994, p. 297).

6. Estas e outras afirmações de Stewart Ranson, inseridas no texto que acima citamos, deram origem a uma interessante polêmica sobre o conceito de mercado em educação. Ver, a esse propósito, James Tooley (1995) e também a resposta de Stewart Ranson (1995).

7. A esse propósito, como observa Basil Bernstein, "el programa estatal de las pruebas de exámenes refleja las tensiones que existen en el seno del conservadurismo actual, así como las que existen entre éste y el sistema educativo. Estas tensiones se vieron coronadas por el rechazo de los profesores a aplicar dichas pruebas a los estudiantes de catorce años y finalmente, por una revisión del conjunto del programa de exámenes" (Bernstein 1994, p. 183). Esse autor refere-se ao boicote que, em 1993, os professores ingleses fizeram aos novos exames nacionais que visavam não apenas verificar os conhecimentos dos estudantes como também estabelecer uma classificação nacional das escolas com base nesses resultados. Um outro autor, a esse propósito refere: "In summer 1993, the national assessment system at ages 7 and 14 broke down as teachers refused en masse to implement it (...). The story of how this happened is a tangled web of issues, some from our educational traditions, some from the intrinsic technical problems of assessment, and some from the ideology of right-wing politics in Britain" (Black 1994, p. 191).

8. Há aqui, como facilmente se depreende, uma racionalidade muito próxima da "legitimação pela performatividade" à qual está hoje sujeito, por exemplo, o ensino superior e a investigação, como assinala Jean-François Lyotard em A condição pós-moderna. Veja-se também, a propósito do Ensino Superior, a análise de Licínio Lima em torno do que designa por "educação contábil" (cf. Lima 1997).

9. David Osborne e Ted Gaebler são autores do livro Reinventing government: How the entrepreneurial spirit is transforming the public sector, considerado uma das obras mais influentes a favor de uma nova filosofia de administração pública nos Estados Unidos, no início dos anos 90. Na revista Public Administration um autor escreve que esse livro "has become as much of a cult book for 
practitioners in government as The pursuit of excellence by Peters and Waterman (1982) did for general British management some years ago. President Clinton, both before and after taking office, warmly praised the book, recommending it as reading for every elected official in America. The title was used as the theme for Vice-President Al Gore's announcement last September of the President's programme for the streamlining and improvement of federal government" (Butler 1994, p. 263). Esse último relatório, a que voltaremos, foi também publicado em português. Ver, a propósito, Al Gore (1994). Também o relatório Porter - Construir as vantagens competitivas de Portugal - recomenda ao governo português que siga as orientações contidas no livro Reinventing government (cf. Monitor Company/M. Porter 1994, p. 85).

10. A partir da década de 1980, o interesse demonstrado pela avaliação, sobretudo por governos neoconservadores e neoliberais de países centrais, começou a ser traduzido pela expressão "Estado avaliador" (cf. Neave 1988, Henkel 1991b, O’Buachalla 1992, Hartley 1993). Para diferentes autores, essa expressão quer significar, em sentido amplo, que o Estado adotou um ethos competitivo, decalcado no que tem vindo a ser designado por neodarwinismo social, passando a admitir a lógica do mercado com a importação para o domínio público de modelos de gestão privada cuja ênfase é posta nos resultados ou produtos dos sistemas educativos. No caso da educação, essa preocupação com o produto, mais do que com o processo, implica formas de avaliação específicas, como o retorno aos exames nacionais, à avaliação aferida ou a outras modalidades de avaliação externas (cf. Afonso 1994, 1995a).

11. Essa questão estaria de algum modo facilitada pelo fato de haver já a tradição em alguns países (como é o caso dos Estados Unidos) de os testes serem comercializados por empresas especializadas. "Chamam-Ihes Evaluation shops porque, com autonomia ou na dependência de fundações e universidades, envolvem sempre uma componente forte de indústria e mercado" (Cardoso 1995, p. 87).

12. Nesse sentido, como refere um autor, "Awareness of the necessity for evaluation has been increased not only by the difficulties of public action, but also by the processes of policy-making in times of crisis. There is no doubt that the 'crisis of the Welfare State' constitutes one of the basic factors giving rise to calls for evaluation" (Duran, Monnier e Smith 1995, p. 58).

13. Trata-se, basicamente, de um modelo híbrido situado algures entre dois outros modelos básicos. Num deles - como referem Merit Granheim e Ulf Lundgren - o Estado tem a responsabilidade de estabelecer um sistema educativo comum para todos os cidadãos, baseado no princípio da igualdade de oportunidades e no qual a avaliação é uma componente importante para garantir a eficácia do sistema e verificar se os objetivos fixados se cumprem. O sistema educativo rege-se por objetivos, regulamentos e avaliações. No outro modelo prevalece o direito individual de escolha sobre o direito do Estado e espera-se que a eficácia da educação seja garantida pela procura. Nesse caso, a avaliação é importante para desenvolver a produtividade, a 
eficácia e para comercializar a educação (cf. Granheim e Lundgren 1991, p. 483). Na nossa interpretação, o modelo de quase-mercado corresponde a uma situação mista.

14. Nesse sentido, e como acentua John A. Codd, "if schools are to become democratic, open and self-reflective communities, the current forces of managerialism and technocratic reductionism in educational evaluation must be resisted vigorously" (Codd 1994, p. 53).

15. Como Boaventura Santos refere, o projeto sociocultural da modernidade assenta em dois pilares fundamentais: o pilar da regulação e o pilar da emancipação. $O$ primeiro é constituído por três princípios (o Estado, o mercado e a comunidade) e o segundo é constituído por três lógicas de racionalidade (a racionalidade estético-expressiva, a racionalidade moral-prática e a racionalidade cognitivoinstrumental) (Santos 1991, p. 23). Tomando como referência este autor, Arriscado Nunes acrescenta: "Por regulação social entendo o complexo de processos através dos quais se realiza a articulação entre diferentes 'mundos' e formas de actividade constitutivas de uma formação social. Seguindo Santos, distingo, nas sociedades 'modernas' (...), três modos de regulação principais: o Estado, o mercado e a comunidade. Cada um destes modos de regulação realiza de maneira diferente a relação entre a economia como processo institucionalizado e as relações sociais globais, através do vínculo privilegiado com um princípio de integração: a redistribuição, a troca e a reciprocidade, respectivamente" (Nunes 1993, p. 110, nota 6).

16. Poderíamos aqui considerar também as chamadas novas formas de avaliação. Não o fazemos por dois motivos: primeiro, porque são formas de avaliação ainda pouco divulgadas entre nós e, mesmo em outros países, ainda parece ser cedo para conhecer todas as suas potencialidades e seus limites; em segundo lugar, e mais importante, porque queremos reafirmar a importância das promessas (não cumpridas) da avaliação formativa numa época em que o retorno conservador aos exames nacionais parece gerar consensos que não deixam de traduzir também alguns retrocessos políticos e pedagógicos.

17. Naturalmente que autores de outras áreas, nomeadamente pedagogos radicais como Paulo Freire (1975) ou Henry Giroux (1986), têm também contribuições decisivas para pensar a questão da emancipação nas suas relações com a educação e a avaliação. A esse propósito, ver também Ana M. Saul (1988).

18. Nesse período, como refere Luiza Cortesão (1992, pp. 89-90), "o impacto das características ideológicas do contexto histórico nas propostas elaboradas ao nível da avaliação" traduz-se, entre outros aspectos, na valorização da consciência dos alunos sobre o seu processo de aprendizagem e na promoção de práticas educativas não selectivas e não discriminatórias".

19. "Portugal é um dos raros países da Europa que não possui momentos de avaliação aferida em todo o ensino básico e secundário. Trata-se de uma situação extraordinariamente grave, uma vez que a falta desses momentos de avaliação aferida conduz à não compreensão da realidade que temos e à con- 
fusão ocasional das análises com os microcosmos com que estamos em contacto e que nos transmitem uma visão da realidade ou cor-de-rosa (...) ou negra (...)" (Martins 1993, p. 226).

20. "Não é admissível que os jovens saiam da escolaridade obrigatória sem que os seus conhecimentos sejam aferidos e testados. Um bom sistema educativo é o que ensina bem e exige a demonstração dos conhecimentos transmitidos. O Partido Popular defende a realização de exames no ensino básico e secundário (...)" (Partido Popular, Programa eleitoral e de governo, 1995, p. 164). Também o relatório Porter para Portugal afirma a esse propósito: "Alterações recentes na política portuguesa no que diz respeito à escolaridade mínima obrigatória reforçam (...) pontos de vista equalitários, retirando ainda mais ênfase aos resultados dos exames. Não existem, actualmente, quaisquer exames padrão até ao nono ano de escolaridade, e não foi criado nenhum mecanismo efectivo para substituir os exames no fornecimento de informação destinada aos alunos, professores, pais e empresas”. E mais à frente: “(...) uma cultura de depreciação da importância dos exames no sistema educativo resultou num mercado de trabalho que não estimula os indivíduos a melhorarem os seus conhecimentos (...)" (Monitor Company/Michael Porter 1994, pp. 91 e 127).

21. Sobre a relação entre a educação e as necessidades do processo e do contexto de acumulação, ver, por exemplo, Dale (1989).

22. Seguimos de perto Boaventura de Sousa Santos relativamente à caracterização do semi-Estado-providência e à questão da não interiorização dos direitos humanos básicos por parte da administração pública (cf., por exemplo, Santos 1990, 1993). Para o campo da educação, ver ainda Afonso (1997b).

\title{
State, market, community and evaluation: Towards a critical rearticulation
}

\begin{abstract}
The central role of evaluation within the context of contemporary educational policies has been the object of many sociological studies, although the signs of their reception in Portugal are still quite tenuous. The present work seeks an understanting of political and economical changes in contexts where the conservative and neoliberal rebirth took place earlier, in order to draw some of their implications over the renewal of the educational and evaluation studies. Since the redefinition of the role of the State and the recovering of the market ideology are two of the essential dimensions of these changes, the role of educational evaluation will be analysed with reference to them. A further (re)articulation will look at evaluation in relation to the community within an emancipatory, rather than regulatory, perspective. From the adopted theoretical framework a
\end{abstract}


succinct reference will be made to the specific nature of changes in educational evaluation occurring in Portugal in the early 90 s.

\section{Bibliografia}

AFONSO, Almerindo J. "A centralidade emergente dos novos processos de avaliação no sistema educativo português". Forum Sociológico $\mathrm{n}^{\circ}$ 4, 1994, pp. 7-18.

- "O novo modelo de gestão das escolas e a conexão tardia à ideologia neoliberal”. Revista Portuguesa de Educação v. 8, $\mathrm{n}^{0} 1$, 1995a, pp. 73-86.

. "A cultura social de discriminação e a avaliação dos alunos do ensino básico". In: PACHECO, J. e ZABALZA, M. (orgs.). A avaliação dos alunos dos ensinos básico e secundário. Braga: Universidade do Minho, 1995b, pp. 89-96.

- "Para uma análise sociológica da avaliação nas políticas educativas. A Reforma Educativa em Portugal e a avaliação pedagógica no ensino básico (1985-1995)". Dissertação de doutoramento. Braga: Universidade do Minho, 1997a.

. "Para a configuração do Estado-providência na educação em Portugal, 1985-1995". Educação, Sociedade \& Culturas nำ 7 , 1997b, pp. 131-156.

ANGULO, J. Félix. "Evaluación del sistema educativo: Algunas respuestas críticas". Cuadernos de Pedagogía no 219, 1993, pp. 8-15.

APPLE, Michael W. "The politics of official knowledge: Does a national curriculum make sense?" Teachers College Record v. 95, $\mathrm{n}^{\circ} 2$, 1993, pp. 222-241.

BERNSTEIN, Basil. "Respuesta a Michael Apple". Revista de Educación no 305, 1994, pp. 179-189.

BLACK, Paul J. "Performance assessment and accountability: The experience in England and Wales". Educational Evaluation and Policy Analysis v. 16, nํ2, 1994, pp. 191-203.

BUTLER, Robin. "Reinventing government: A symposium". Public Administration, v. 72, 1994, pp. 263-270. 
CARDOSO, Abílio. “'Avaliação aferida': Que destino?”. In: PACHECO, J. e ZABALZA, M. (orgs.). A avaliação dos alunos dos ensinos básico e secundário. Braga: Universidade do Minho, 1995, pp. 83-88.

CARL, Jim. "Parental choice as national policy in England and the United States". Comparative Education Review v. 38, no 3, 1994, pp. 294-322.

CHITTY, Clyde. "Consensus to conflict: The structure of educational decision-making transformed". In: SCOTT, D. (org.). Accountability and control in educational settings. Londres: Cassell, 1994, pp. 8-31.

CHUBB, John e MOE, Terry. Politics, markets, and America's schools. Washington: Brookings, 1990.

CODD, John A. "Educational reform and the contradictory discourses of evaluation". Evaluation and Research in Education v. 8, $\mathrm{n}^{\mathrm{os}} 1$ e 2, 1994, pp. 41-54.

COOPER, Phillip. "Toward the hybrid state: The case of environmental management in a deregulated and re-engineered state". International Review of Administrative Sciences v. 61, nº 2, 1995, pp. 185-200.

CORTESÃO, Luiza. "Nos bastidores da avaliação dos alunos". In: Decisões nas políticas e práticas educativas. Porto: Sociedade Portuguesa de Ciências da Educação, 1992, pp. 83-92.

DALE, Roger. The State and education policy. Milton Keynes: Open University Press, 1989.

. "A promoção do mercado educacional e a polarização da educação". Educação, Sociedade \& Culturas nº 2, 1994, pp. 109-139.

DURAN, Patrice; MONNIER, Eric e SMITH, Andy. "Evaluation à la française: Towards a new relationship between social science and public action". Evaluation v. 1, ํㅜ 1, 1995, pp. 45-63.

FREIRE, Paulo. Pedagogia do oprimido. $2^{\mathrm{a}}$ ed. Porto: Afrontamento, 1975.

GAMBLE, Andrew. The free economy and the strong State. $2^{\mathrm{a}}$ ed. Londres: Macmillan, 1994.

GIROUX, Henry. Teoria crítica e resistência em educação. Petrópolis: Vozes, 1986.

GORE, Al (coord.). Reinventar a administração pública. Lisboa: Quetzal, 1994.

GRANHEIM, Merit K. e LUNDGREN, UIf P. "Steering by goals and evaluation in the norwegian educational system: A report from 
the EMIL project”. Journal of Curriculum Studies v. 23, $\mathrm{n}^{\circ} 6,1991$, pp. 481-505.

HABERMAS, Jürgen [1988]. Legitimation crisis. Cambridge: Polity Press, 1973.

HANF, Kenneth. "The political economy of ecological modernization". In: MORAN, M. e PROSSER, T. (orgs.). Privatization and regulatory change in Europe. Buckingham: Open University Press, 1994, pp. 126-143.

HARGREAVES, Andy. "The crisis of motivation and assessment". In: HARGREAVES, A. e REYNOLDS, D. (orgs.). Education policies: Controversies and critiques. Londres: Falmer Press, 1989, pp. 41-63.

HARTLEY, David. "The evaluative state and self-management in education: Cause for reflection?" In: SMYTH, J. (org.). A socially critical view of the self-managing school. Londres: Falmer Press, 1993, pp. 99-115.

HATCHER, Richard. "Market relationships and the management of the teachers". British Journal of Sociology of Education v. 15, $\mathrm{n}^{\circ} 1$, 1994, pp. 41-61.

HENKEL, Mary. Government, evaluation and change. Londres: Jessica Kingsley Publ., 1991a.

. "The new 'evaluative state'”. Public Administration, v. 69, 1991b, pp. 121-136.

HOUSE, Ernest R. Professional evaluation: Social impact and political consequences. Londres: Sage, 1993.

LE GRAND, Julian. "Quasi-markets and social policy". The Economic Journal, v. 101, set. 1991, pp. 1.256-1.267.

LIMA, Licínio C. "O paradigma da educação contábil: Políticas educativas e perspectivas gerencialistas no ensino superior em Portugal". Revista Brasileira de Educação no 4, 1997, pp. 43-59.

LUND, Brian. "Robert Nozick and the politics of social welfare". Political Studies, vol. XLIV, 1996, pp. 115-122.

LYOTARD, Jean-François. A condição pós-moderna. Lisboa: Gradiva, s./d.

MARTINS, Guilherme d'Oliveira. "Intervenção". In: A educação em Portugal no horizonte dos anos 2000 (Actas do Seminário). Lisboa: CNE, 1993, pp. 224-230. 
MONITOR COMPANY/PORTER, Michael. Construir as vantagens competitivas de Portugal. Lisboa: Forum para a Competitividade, 1994.

NEAVE, Guy. "On the cultivation of quality, efficiency and enterprise: An overview of recent trends in higher education in Western Europe, 1986-1988". European Journal of Education $\mathrm{n}^{\mathrm{os}}$ 1/2, 1988, pp. 7-23.

NOZICK, Robert [1988]. Anarquía, Estado y utopía. México: Fondo de Cultura Económica, 1974.

Meditaciones sobre la vida. Barcelona: Gedisa, 1992.

NUNES, J. Arriscado. "Polanyi revisitado: Modos de regulação, inovação tecnológica e contra-movimento protector na era do capitalismo desorganizado". In: Estruturas sociais e desenvolvimento. Lisboa: Fragmentos/APS, v. 1, 1993, pp. 97-114.

O'BUACHALLA, Seamus. "Self-regulation and the emergence of evaluative state: Trends in irish higher education policy, 1987-1992". European Journal of Education, v. 27, $\mathrm{n}^{\text {os }}$ 1/2, 1992, pp. 69-78.

OSBORNE, David e GAEBLER, Ted. Reinventing government: How the entrepreneurial spirit is transforming the public sector. Wokingham: Addison-Wesley, 1992.

PARTIDO POPULAR. "Vamos dar lugar a Portugal". Programa eleitoral e de governo, 1995.

PETERS, Michael. "Governamentalidade neoliberal e educação". In: SILVA, T. Tadeu da (org.). O sujeito da educação: Estudos foucaultianos. Petrópolis: Vozes, 1994, pp. 211-224.

RANSON, Stewart. "Markets or democracy for education". British Journal of Educational Studies v. XXXXI, nº 4, 1993, pp. 333-352.

. "Public institutions for cooperative action: A reply to James Tooley". British Journal of Educational Studies v. 43, no 1, 1995, pp. $35-42$.

SALTER, Brian. "The private sector and the NHS: Redefining the welfare state". Policy and Politics v. 23, ํㅜ 1, 1995, pp. 17-30.

SANTOS, Boaventura de Sousa. O Estado e a sociedade em Portugal (1974-1988). Porto: Afrontamento, 1990.

"Ciência". In: CARRILHO, Manuel (org.). Dicionário do pensamento contemporâneo. Lisboa: Dom Quixote, 1991, pp. 23-43. 
. "O Estado, as relações salariais e o bem-estar social na semiperiferia: O caso português". In: SANTOS, B.S. (org.). Portugal: Um retrato singular. Porto: Afrontamento, 1993, pp. 15-56.

. Pela mão de Alice. O social e o político na pós-modernidade. Porto: Afrontamento, 1994.

SAUL, Ana Maria. Avaliação emancipatória. São Paulo: Cortez/Autores Associados, 1988.

SCHWARZ, Bill. "Los años de gobierno Thatcher". In: MILIBAND, R.; PANITCH, L. e SAVILLE, J. (orgs.). El neoconservadurismo en Gran Bretaña y Estados Unidos: Retórica y realidad. Valencia: Edicions Alfons el Magnànim, 1992, pp. 91-135.

STOER, Stephen R. "O Estado e as políticas educativas: Uma proposta de mandato renovado para a escola democrática". Revista Crítica de Ciências Sociais nํ 41, 1994, pp. 3-33.

STOER, Stephen R. e ARAÚJO, Helena C. Escola e aprendizagem para o trabalho num país da (semi)periferia européia. Lisboa: Escher, 1992.

TOOLEY, James. "Markets or democracy for education? A reply to Stewart Ranson". British Journal of Educational Studies v. 43, no 1, 1995, pp. 21-34.

WEILER, Hans N. "Legalization, expertise, and participation: Strategies of compensatory legitimation in educational policy". Comparative Education Review v. 27, no 2, 1983, pp. 259-277.

WHITAKER, Reg. "Neoconservadurismo y Estado". In: MILIBAND, R.; PANITCH, L. e SAVILLE, J. (orgs.). El neoconservadurismo en Gran Bretaña y Estados Unidos: Retórica y realidad. Valencia: Edicions Alfons el Magnànim, 1992, pp. 9-46. 